\title{
PAPER
}

\section{Small therapeutic molecules for the treatment of inflammatory bowel disease}

\section{S J H van Deventer}

Gut 2002;50(Suppl III):iii47-iii53

New therapies for inflammatory bowel disease are needed, because standard therapies fail to induce remission in about $30 \%$ of patients, and because of the relative inefficacy of current maintenance therapies. This review summarises the current status of the development of small therapeutic molecules for inflammatory bowel disease.

Correspondence to: S J H van Deventer, Department of Hepato-Gastroenterology, Academic Medical Center, Meibergdreef 9, $1105 \mathrm{AZ}$

Amsterdam, Netherlands
U ntil the introduction of anti-inflammatory therapies in the midle of the last century, inflammatory bowel disease was a potentially lethal disorder that could only be treated by surgery. The discovery of the therapeutic efficacy of salazopyrine and corticosteroids for ulcerative colitis and subsequently Crohn's disease has importantly changed the prognosis of patients with inflammatory bowel disease, and the life expectancy of patients with ulcerative colitis and Crohn's disease is now similar to healthy subjects. Immunosuppressive drugs, in particular azathioprine (6-mercaptopurine) and methotrexate are effective for remission induction and maintenance of Crohn's disease; azathioprine is also used for remission maintenance of ulcerative colitis. With the exception of cyclosporine, which has no efficacy in Crohn's disease, and limited efficacy in severe ulcerative colitis, with the exception of variations on the corticosteroid/ salazopyrine theme, no effective small molecules have been developed for the treatment of inflammatory bowel disease in the past 50 years. Recently, "biologicals" (monoclonal antibodies, therapeutic peptides, antisense oligonucleotides) have attracted significant interest as novel antiinflammatory or immunomodulating approaches in inflammatory bowel disease, and at least one such approach (a tumour necrosis factor $\alpha$ (TNF $\alpha$ ) binding monoclonal antibody) has been a breakthrough in the treatment of therapy refractory Crohn's disease. However, compared to small molecules, "biologicals" have certain disadvantages, including the restriction to non-oral routes of administration, immunogenicity, and high cost. Moreover, new therapies for inflammatory bowel disease are still needed, because standard therapies fail to induce remission in about $30 \%$ of patients, and because of the relative inefficacy of current maintenance therapies. In this paper, the current status of the development of small therapeutic molecules for inflammatory bowel disease is reviewed.

\section{EICOSANOIDS}

The search for new targets for anti-inflammatory therapies in inflammatory bowel disease was ini- tiated by the characterisation of the production of specific eicosanoids in the inflamed mucosal in the late 1970s. It soon became apparent that certain prostaglandins produced by the inflamed mucosa, in particular prostaglandin $E_{2}$, had anti-inflammatory activities; this explained the harmful effects of non-steroidal antiinflammatory drugs (NSAIDs) in inflammatory bowel disease. ${ }^{12}$ Inducible cyclooxygenase (COX) has been implicated in the maintenance of mucosal tolerance, which suggests that COX-2 specific NSAIDS may also be contraindicated in inflammatory bowel disease. ${ }^{3-5}$ Using rectal dialysis as a tool to measure mucosal eicosanoid production, it was shown that administration of indomethacin and corticosteroids promptly reduced the production of prostaglandins, but only corticosteroid administration reduced the rectal dialysate leukotriene B4 concentration. Leukotriene B4 is a potent inflammatory mediator and activates neutrophils at low concentrations; this finding suggested that leukotrienes, but not prostaglandins, were proinflammatory in ulcerative colitis. This hypothesis received further support from studies which indicated that sulphasalazine and 5-aminosalicylic acid also inhibit leukotriene (LT) production. Indeed, a specific benzothiophene hydroxyurea 5-lipoxygenase inhibitor, zileuton, reduced LTB4 production, neutrophil influx, and mucosal injury in several animal models of inflammatory bowel disease. ${ }^{67}$ Zileuton also inhibited LTB4 production in the human inflamed colon, and its ability to maintain remission (compared to placebo and mesalazine) in patients with ulcerative colitis was subsequently investigated. This study confirmed that mesalazine was superior to placebo in remission maintenance in ulcerative colitis, but failed to show that zileuton was better that placebo. ${ }^{8}$ As a result, further development of zileuton (or any other 5-lipoxygenase inhibitor) for inflammatory bowel disease was discontinued.

Ridogrel is an oral inhibitor of thromboxane synthase, as well as a thromboxane receptor

Abbreviations: COX, cyclooxygenase; CREB, CAMP response element binding protein; IFN, interferon; IL, interleukin; JNK, c-JUN NH${ }_{2}$ terminal kinase; LPS, lipopolysaccharide; LT, leukotriene; MAP, mitogen activated protein; NF, nuclear factor; NO, nitric oxide; NSAID, non-steroidal anti-inflammatory drug; PAF, platelet activating factor; PDE, phosphodiesterase; PPAR, peroxisome proliferator activated receptor; SAPK, stress activated MAP kinase; TACE, TNF $\alpha$ converting enzyme; TNBS, trinitro-benzene-sulphonic acid; TNF $\alpha$, tumour necrosis factor $\alpha$ 
antagonist, that was initially developed as an antagonist of blood platelet aggregation. ${ }^{9}{ }^{10}$ Treatment of ulcerative colitis patients with ridogrel resulted in a reduction of the mucosal production of thromboxane $\mathrm{A} 2$, but prostaglandin $\mathrm{E}_{2}$ release was not affected. ${ }^{11-13}$ Unfortunately, ridogrel did not decrease mucosal production of interleukin 6 (IL-6) and TNF $\alpha$, and the disappointing results of (unpublished) controlled clinical trials led to the discontinuation of further development for treatment of inflammatory bowel diseases.

Platelet activating factor (PAF) is a potent stimulator of neutrophils and endothelial cells (being intimately involved in neutrophil migration through endothelial monolayers), and PAF and TNF $\alpha$ reciprocally and synergistically induce inflammation. In chimpanzees, PAF antagonism has antiinflammatory effects and reduces endotoxin induced TNF $\alpha$ release..$^{14}$ A potential role of PAF as mediator of mucosal inflammation was suggested by studies that showed increased mucosal PAF production in experimental inflammatory bowel disease and in ulcerative colitis. ${ }^{15}{ }^{16}$ Subsequently, several PAF antagonists were shown to prevent mucosal damage in various animal models of mucosal inflammatory disease. ${ }^{17} 18$ However, an (unpublished) controlled clinical trial failed to show a therapeutic effect of intravenous administration of BB 882 (a potent PAF antagonist) in fulminant ulcerative colitis. A molecule that is composed of a PAF antagonist linked to 5 -acetylsalicylic acid is currently being developed for inflammatory bowel disease.

Taken together, these data may be interpreted to indicate that eicosanoids (leukotrienes, PAF, thromboxane A2) do not represent useful targets for therapies of inflammatory bowel disease. This conclusion should be made with some caution, because several of the negative studies have not been published in detail, and because some of the inhibitors used (zileuton, ridogrel) incompletely inhibited the production of the target eicosanoid.

\section{NITRIC OXIDE}

In active ulcerative colitis and Crohn's disease the intestinal mucosal production of nitric oxide $(\mathrm{NO})$ is greatly increased. ${ }^{19-21} \mathrm{NO}$ production in the inflamed mucosa has several cellular sources, and increased NO production in the muscularis propria has been implicated as a mechanism for the impaired motility and dilatation that is the hallmark of toxic megacolon. ${ }^{22-25}$ Interestingly, corticosteroids do not seem to reduce the mucosal expression of NO synthase in patients with ulcerative colitis. ${ }^{26}$ These findings are in line with the observation that certain pathogenic bacteria induce NO production in intestinal epithelial cells through a mechanism that is NFKB dependent, but corticosteroid insensitive, and the finding that curcumin dependent reduction of epithelial $\mathrm{NO}$ production is a result of NFKB activation (see below). ${ }^{27} 28$ Excessive production of NO may cause inflammation through formation of intermediaries such as peroxynitrite, and in rats intrarectal instillation of peroxynitrite caused mucosal inflammation. ${ }^{29}$ Trinitro-benzene-sulphonic acid (TNBS) induced colitis in rats is characterised by greatly increased NO production, and in this model interference with NO production by oral administration of L-NAME had impressive protective effects. ${ }^{30}{ }^{31}$ However, it well known that NO also has protective activities in TNBS induced colitis, and pretreatment with L-NAME before induction of colitis, increased mucosal damage. $^{32}$ Similar observations were reported in HLA-B27/ human $\beta_{2}$ microglobulin transgenic rats, and conflicting data have been published concerning efficacy of the NO blocker aminoguanidine in TNBS induced colitis. ${ }^{33-35}$ An NO releasing preparation of mesalazine was superior to mesalazine in a rat model of colitis, and inhibited neutrophil adherence and the production of IL- 1 and interferon $\gamma($ IFN $\gamma) .^{36}$ In spontaneously occurring colitis in Rhesus macaques, administration of various blockers of inducible NO synthase did not alter the clinical severity. ${ }^{37}$
In conclusion, NO has many physiological functions in the human gut, and the production of NO by intestinal epithelial cells via inducible NO synthase is often observed in the non-diseased bowel. ${ }^{38}$ At high concentrations, NO may cause damage to the intestinal mucosal, through the formation of intermediaries such as peroxynitrite. It is extremely difficult to design a therapeutic strategy that would target only excessive NO production, and both protective and harmful effects of NO blockade have been observed in animal models. For this reason, it is not likely that currently available NO blockers will be effective in inflammatory bowel disease, but no clinical data have been reported.

\section{PPAR $\gamma$}

Peroxisome proliferator activated receptor $\gamma(\operatorname{PPAR} \gamma)$ is a nuclear receptor that was initially identified as a major regulator of adipose differentiation and metabolism, and later as a pivotal receptor for immunity and inflammation. ${ }^{39}$ Stimulation of PPAR $\gamma$ in macrophages results in inhibition of nuclear factor $\kappa \mathrm{B}(\mathrm{NF} \kappa \mathrm{B})$, which is associated with induction of apoptosis. ${ }^{40}$ In addition, activation of PPAR $\gamma$ causes inhibition of the STAT and AP-1 signalling pathways, and together this explains the PPAR $\gamma$ mediated reduction of IL-2, IL-6, IL-8, TNF $\alpha$, IL-12, and metalloproteinase release. ${ }^{41} 42$ These results are likely to be important for inflammatory bowel disease, because the colon mucosa expresses high concentrations of PPAR $\gamma{ }^{43}{ }^{44}$ Mice that are deficient for PPAR $\gamma$, or the RXR retinoid receptor, which is a heterodimeric PPAR $\gamma$ partner, display an increased sensitivity to hapten induced colitis. ${ }^{45}$ In addition, administration of agonistic ligands of the two receptors (synergistically) attenuated the severity of TNBS colitis in mice; this was shown to be associated with a reduction of activation of the NFKB, colonic MAP p38 activity, and JNK (c-JUN $\mathrm{NH}_{2}$ terminal kinase) activation, resulting in reduced production of proinflammatory cytokines. ${ }^{45}$ These results are of great importance in view of the fact that PPAR $\gamma$ activating small molecules have been developed as antidiabetic and antiatherogenic drugs, and are currently available. ${ }^{46-50}$

\section{PHOSPHODIESTERASE INHIBITORS}

Cyclic AMP (CAMP) is involved in regulation of the expression of several proinflammatory cytokine genes via phosphorylation of cAMP response element binding protein (CREB)..$^{51}$ Phosphodiesterase 4 (PDE4) is an important regulator of the intracellular CAMP concentration, and several PDE4 inhibitors have anti-inflammatory and immunomodulating effects. PDE4 inhibitors, at relatively high concentrations, inhibit the production of proinflammatory cytokines, including TNF $\alpha$, in vitro as well as in vivo, most likely by reducing transcription of the gene. ${ }^{5354}$ Hence, the mechanism of action differs from the effects of corticosteroids, that also inhibit post-transcriptional events, in particular translational efficacy. ${ }^{55}{ }^{56}$ It should be noted that the first generation PDE4 inhibitors, including pentoxifylline, amrinone, and rolipram, were not primarily designed to inhibit cytokine production. Indeed, these drugs have many other effects, including attenuation of activation of neutrophils, endothelial cells, and blood platelets. ${ }^{57-60}$ Apart from inhibiting inflammation that results from activation of the innate immune response, inhibition of PDE4 also has an effect on T lymphocyte mediated inflammation. For example, rolipram inhibited IL-15 induced expression of cell adhesion molecules and interfered with PAF and IL-8 directed T lymphocyte chemotaxis. ${ }^{61}{ }^{62}$

PDE4 inhibitors have been reported to have protective effects in many animal models of (intestinal) inflammation, including inflammatory bowel disease. ${ }^{63-68}$ However, the reported data are inconsistent, and several investigators have been unable to find an association between the protective effects and mucosal production of TNF $\alpha$. Moreover, at the relatively high doses required to achieve a TNF $\alpha$ inhibitory 
effect in primates, including humans, first generation PDE4 inhibitors cause gastrointestinal side effects that are in part mediated by a stimulation of gastric acid production. A second generation PDE4 inhibitor has been synthesised that apparently lacks this side effect, but has not been tested in inflammatory bowel disease. ${ }^{69} 70$

Only one PDE4 inhibitor (oxpentifylline, a pentoxifylline analogue) has been systematically studied in Crohn's disease, and no clinical efficacy was found despite a reduction of the capacity of peripheral blood mononuclear cells to produce TNF $\alpha .^{71} 72$

In conclusion, phosphodiesterase inhibitors, in particular PDE4 specific compounds, have multiple anti-inflammatory effects and, at high concentrations, interfere with the production of proinflammatory cytokines. First generation PDE4 inhibitors are relatively weak inhibitors of TNF transcription and cause gastrointestinal side effects. A single study using oxpentifylline in Crohn's disease did not show clinical efficacy.

\section{THALIDOMIDE}

Thalidomide was first synthesised in 1954 and soon marketed as a sedative. Because of the induction of severe birth defects thalidomide was withdrawn from the market in the early 1960s. Meanwhile, it had been serendipitously found that patients with erythema nodosum leprosum responded well to thalidomide therapy; this finding was confirmed in a controlled clinical trial. ${ }^{73}{ }^{74}$ For many years the mechanism of action remained unknown, but in 1991 it was reported that thalidomide reduced the production of TNF $\alpha$ by lipopolysaccharide (LPS) stimulated monocytes. ${ }^{75}$ Thalidomide does not affect signal transduction pathways (for example, activation of NFKB) that induce TNF transcription, but increases TNF $\alpha$ mRNA degradation. ${ }^{7677}$ Thalidomide has efficacy in several $\mathrm{TNF} \alpha$ mediated diseases, but it is uncertain whether the mechanism of action is a result of interference with the production of TNF $\alpha$. It should be noted that thalidomide is a relatively weak $\mathrm{TNF} \alpha$ inhibitor, and even at very high drug concentrations, inhibition of TNF $\alpha$ production by peripheral blood mononuclear cells and $\mathrm{T}$ lymphocytes is incomplete. ${ }^{78}$ Recently, several thalidomide derivatives have been synthesised that are reported to have a much increased TNF $\alpha$ inhibiting effect. ${ }^{79}{ }^{80}$ These compounds do not affect TNF $\alpha$ mRNA degradation and do not interfere with NFKB activation, but have been shown to be PDE4 inhibitors. ${ }^{79} 80$ This class of thalidomide derivatives mainly affects macrophages and monocytes, reducing TNF $\alpha$ and stimulating IL- 10 production, but does not affect T lymphocyte activation. ${ }^{81} \mathrm{~A}$ second class of thalidomide derivatives strongly boosts $\mathrm{T}$ lymphocyte activation, and production of IL-2 and IFN $\gamma$, and therefore is considered to be immunostimulatory. ${ }^{81}$ The parent compound, thalidomide, has well known $\mathrm{T}$ lymphocyte co-stimulatory effects, and in healthy volunteers, thalidomide strongly boosts $\mathrm{T}$ lymphocyte proliferation and IFN $\gamma$ production, while having a weak inhibitory effect on LPS induced TNF $\alpha$ production. ${ }^{82}{ }^{83}$ In thalidomide treated patients with pulmonary tuberculosis, TNF $\alpha$ production was reported to be reduced, but in HIV positive patients with tuberculosis, thalidomide treatment either increased or did not affect TNF $\alpha$ production. ${ }^{84}{ }^{85}$ The latter study did show an increase of soluble IL-2 receptor, IFN $\gamma$, and PPD dependent T lymphocyte proliferation, following thalidomide therapy, indicative of immunostimulatory effects. ${ }^{85}$ Finally, in a prophylactic study, thalidomide therapy increased the incidence of graft versus host disease and decreased survival. ${ }^{86}$ Hence, in healthy volunteers, as well as in immunosuppressed patients, the therapeutic profile of thalidomide is characterised by immunostimulatory effects rather than by suppression of TNF $\alpha$ production.

Thalidomide has been reported to have beneficial effects in erythema nodosum leprosum, in complications of HIV (tuberculosis, aphthous stomatitis), in Behcet's syndrome, and in pyoderma gangrenosum, but its efficacy in rheumatoid arthritis is equivocal. ${ }^{87-97}$ Following reports of healing of oral ulcers in Crohn's disease by thalidomide treatment, the efficacy of thalidomide in active (steroid dependent) Crohn's disease was investigated in two small uncontrolled studies; both suggested therapeutic efficacy ${ }^{98-100}$ In the first study, 12 patients with active Crohn's disease, despite treatment with at least $20 \mathrm{mg}$ prednisone, were included. The first six patients received $50 \mathrm{mg}$, the last six patients $100 \mathrm{mg}$ thalidomide daily for 12 weeks. In seven patients clinical improvement was observed at week 4, and two patients had a complete clinical remission. After the fourth week of treatment steroids were tapered, and could be completely discontinued in almost half of the patients. ${ }^{101}$ A second study included 22 patients with active Crohn's disease, who were treated with either $200 \mathrm{mg}$ ( 18 patients) or $300 \mathrm{mg}$ (two patients) of thalidomide at bedtime. Of the 22 included patients, 14 were still in the study at 12 weeks, and nine were in clinical remission (six with fistulas, three with luminal disease)..$^{99}$ Another open label follow up study in five children with Crohn's disease reported a response in four, that was maintained for a period of 19-24 months; steroids were discontinued in all four responders. ${ }^{98}$

Thalidomide has several side effects. Clearly, the well known teratogenicity precludes its usage in pregnant women, and mandates the use of adequate birth control. However, the efficacy of birth control is not complete, and even in phase II drug development, some women who have been adequately advised to use birth control nonetheless become pregnant. Other thalidomide related side effects include neuropathy, rash, and drowsiness. It seems that such side effects are of minor importance in life threatening diseases, such as tuberculosis in HIV infected patients, or when therapeutic alternatives are not available, such as in therapy refractory pyoderma gangrenosum. The results from the small clinical trials in chronic inflammatory disease (rheumatoid arthritis, Crohn's disease) seem to indicate that a relatively large proportion (up to $30 \%$ ) of the enrolled patients fail to complete a three month thalidomide course because of side effects. ${ }^{97} 99$

Although there is no published evidence that the efficacy of thalidomide is related to a reduction of (mucosal) TNF $\alpha$ production, a controlled clinical study with one of the PDE4 specific thalidomide derivatives has been initiated targeting patients with active Crohn's disease. Until the results of controlled clinical trials become available, the use of thalidomide should be restricted to severe therapy refractory complications of inflammatory bowel disease, including pyoderma gangrenosum and extensive oral ulceration.

\section{TNF $\alpha$ CONVERTING ENZYME INHIBITORS}

The post-translational processing of TNF $\alpha$ includes cleavage of the membrane bound TNF precursor molecule by a metalloproteinase. ${ }^{102-104}$ The responsible enzyme, which acts at the cell membrane, has been identified as TNF $\alpha$ converting enzyme (TACE; ADAM17), and is a member of the extensive ADAM (a disintegrin and metalloproteinase) family of proteases. Apart from TNF $\alpha$, TACE cleaves several other membrane bound proteins, including CD16, CD27, CD30, the two TNF receptors, and itself. ${ }^{105-107}$ TACE is an interesting target for therapy of chronic inflammatory diseases, because structurefunction relations are well known and have allowed the development of (hydroxamate based) small molecular inhibitors. Indeed, in a phase II clinical trial in low dose endotoxaemia in volunteers, TACE inhibition dramatically reduced the amount of LPS induced circulating TNF $\alpha .{ }^{108}$ The TACE inhibitors that are currently available for use in clinical trials are not very specific and also inhibited other ADAM family members. In view of the known pathogenic importance of metalloproteinases for the induction of damage to the inflamed intestinal mucosa, this might be a desired effect. ${ }^{109-111}$ Indeed, the efficacy of the metalloproteinase marimastat in experimental colitis 
was suggested to be dependent on metalloproteinase inhibition rather than a reduction of TNF $\alpha$ production. ${ }^{112}$ Unfortunately, non-specific metalloproteinase inhibitors either cause prohibitive side effects, or have been ineffective in chronic inflammatory disease. ${ }^{113}$ Another point of concern has been the prevention of TNF receptor shedding by TACE inhibition. Following activation of target cells by TNF $\alpha$, both TNF $\alpha$ receptors are rapidly shed by activation of TACE, and as a consequence these cells become TNF $\alpha$ unresponsive. In addition, soluble TNF receptors retain the ability to bind TNF $\alpha$; this is considered to be a natural TNF $\alpha$ scavenging principle. In rheumatoid synovial membrane cell cultures, treatment with a TACE inhibitor reduced TNF $\alpha$ production, but paradoxically increased the release of IL-1 $\beta$, IL-6, and IL-8, which was suggested to be related to a reduction of the release of both TNF receptors. ${ }^{114}$ Similar, albeit relatively minor, effects have been observed in low dose endotoxaemia. ${ }^{108}$

In conclusion, TACE remains an interesting target for the development of anti-inflammatory small molecules. However, further development requires generation of molecules with much greater TACE specificity than those that have been studied to date. It should be noted that the effects of specific TACE inhibitors are not restricted to membrane bound TNF $\alpha$, because several other membrane expressed molecules are cleaved by TACE.

\section{SIGNAL TRANSDUCTION INHIBITORS}

Several interacting cascades of signalling molecules regulate cellular death and survival. The importance of these signal transduction pathways for cytokine production and inflammation became apparent through two independent lines of research that led to the identification of MAP kinases as regulators of the transcription and translation of TNF $\alpha$. The first line of research aimed at the identification of intracellular targets for a class of pyridinyl-imidazole compounds that inhibited the production of TNF $\alpha$ and IL-1 $\beta$; the second line investigated the nature of the proteins that were tyrosine phosphorylated following cellular stress. ${ }^{115-117}$ The results of these studies converged on the notion that the $38 \mathrm{kD}$ mitogen activated protein kinase (MAP p38) is a key enzyme, that regulates cell responses to cytokine stimulation, osmotic stress, and radiation injury. It is now known that at least three tightly linked signal transduction pathways regulate the production of proinflammatory cytokines - that is, the NFKB, MAPK p38, and JNK pathways. ${ }^{18-121}$ Not only are these pathways regulators of cytokine production, all three pathways also act downstream of several receptors of proinflammatory cytokines. There is now evidence that activation of all these pathways occurs in inflammatory bowel disease, and with the exception of JNK, more or less specific inhibitors are available.

In resting cells, NFKB is localised within the cytoplasm, being bound by IKB. Activation of IkB kinases (IKK) leads to phosphorylation of $\mathrm{I} \kappa \mathrm{B}$ and subsequent degradation in the proteasome, allowing NFKB to enter the nucleus and bind to NFKB specific DNA sequences that are found in the promoter of many proinflammatory cytokine genes. It should be noted that the NFKB family of proteins includes several members that are able to form various homo- and heterodimers that may have different effects. ${ }^{122}{ }^{123}$ Activation of NFאB does occur in ulcerative colitis and Crohn's disease, but the cells in which $\mathrm{NFKB}$ is translocated into the nucleus differ (lamina propria cells in Crohn's disease and ulcerative colitis and in epithelial cells in ulcerative colitis). ${ }^{124}{ }^{125}$ In intestinal epithelial cells, $\mathrm{NFKB}$ is an important regulator of chemokine (IL-8) production as well as ICAM- 1 expression, and the pathogenicity of certain bacteria is in part a result of the induction of NFKB in epithelial cells. ${ }^{126}{ }^{127}$ It has recently been found that certain non-pathogenic bacteria prevent the translocation of $\mathrm{NFKB}$ (by interfering with the degradation of $\mathrm{I} \kappa \mathrm{B}$ ) in intestinal epithelial cells; this may be an explanation for the efficacy of certain "probiotics". ${ }^{128}$ In both T lymphocyte mediated and epithelial cell dependent animal models of inflammatory bowel disease, interference with the NFKB pathway by administration of antisense p65 (an NFKB member) oligonucleotides had a protective effect. ${ }^{129} 130$ Several currently used drugs, including corticosteroids and aspirin, are known to target $\mathrm{NF \kappa B}$, and several redox sensitive molecular interactions that are necessary for NFKB translocation can be relatively easily targeted by small molecules. ${ }^{131}$ Because aspirin is not effective and many patients are refractory to corticosteroids, it is clear that not all these approaches will be effective in inflammatory bowel disease. Apart from mentioned potential (anti-inflammatory) regulation of NFKB in intestinal epithelial cells, food derived small molecules may also regulate intestinal NFKB translocation. An example is the inhibition of $\mathrm{NF \kappa B}$ activation (by interfering with IKB kinase activation) in intestinal epithelial cells by the flavonoid curcumin, and by food derived butyrate. ${ }^{132-134}$ To date no controlled clinical trials using specific inhibitors of $\mathrm{NF \kappa B}$ in inflammatory bowel disease have been reported.

Activation of MAPK as well as JNK in active inflammatory bowel disease has been recently reported. ${ }^{135}$ Several generations of MAP p38 targeting small molecules have been tested in animal models of inflammation, and efficacy has been shown in experimental arthritis. ${ }^{136} 137$ We have recently found that a first generation MAP p38 kinase inhibitor (SB 203580) did inhibit IFN $\gamma$, but not TNF $\alpha$ production in T lymphocyte mediated experimental colitis and did not prevent mucosal damage (unpublished results). At present it is unclear why MAP p38 inhibition by SB 203580 failed to improve the outcome of experimental colitis. It should be noted that this compound blocks activation by blinding to the MAP p38 ATP binding pocket, but the drug does not prevent p38 phosphorylation. In several experimental systems this paradoxically leads to a profound activation of upstream kinases that may cause inflammation through activation of parallel signal transduction pathways. ${ }^{138}$ If this hypothesis is correct, a better strategy would be the inhibition of MAP kinase activation at a more proximal level. Alternatively, as it is known that MAP p38 activation is a negative regulator of proliferation of certain cells, its inhibition may lead to uncontrolled proliferation. ${ }^{139}$

c-JUN $\mathrm{NH}_{2}$ terminal kinases (JNK, also known as stress activated MAP kinase, SAPK) constitute a family of MAP signal transduction proteins, that are involved in cell proliferation, apoptosis, morphogenesis, and tumour formation. ${ }^{119} \mathrm{~A}$ recent phase II study suggested that JNK inhibition may have protective effects in severe Crohn's disease, reducing circulating $\mathrm{C}$ reactive protein concentrations, and causing mucosal healing. ${ }^{140}$ Several controlled clinical trials using blockers of MAP p38 and JNK in active inflammatory bowel disease have been planned.

\section{CONCLUSIONS}

Despite a clear unmet need for new effective and non-toxic therapies for induction and maintenance of remission, no therapeutic small molecules for the treatment of inflammatory bowel disease have been introduced in the past decades. Eicosanoids (thromboxane A2, leukotrienes, and PAF) are produced at an increased rate by the inflamed bowel mucosal, and are considered to have proinflammatory effects. In several animal models, compounds that inhibit these proinflammatory eicosanoids were protective, but clinical efficacy has been disappointing. PDE4 inhibitors have anti-inflammatory effects, but the inhibition of the production of proinflammatory cytokines is relatively weak, and gastrointestinal side effects are common. Thalidomide has complex biological effects, including the stimulation of (a subset of) T lymphocytes, and inhibition of IL-12 and TNF $\alpha$; it remains to be seen which of these effects is responsible for the therapeutic efficacy in 
several T lymphocyte mediated diseases. Two uncontrolled studies have reported that thalidomide may be effective in steroid refractory Crohn's disease; these data need to be confirmed.

New promising small molecules for the treatment of inflammatory bowel disease include activators of PPAR $\gamma$, which result in an inhibition of signal transduction pathways that are important for proinflammatory cytokine production. In addition, small molecules that directly interfere with the NFKB, JNK, and MAPK pathways have promising effects in animal models. One of these compounds may have important therapeutic efficacy in severe Crohn's disease; this may herald an emerging class of new therapeutic small molecules for the treatment of inflammatory bowel disease.

\section{REFERENCES}

1 Evans JM, McMahon AD, Murray FE, et al. Non-steroidal anti-inflammatory drugs are associated with emergency admission to hospital for colitis due to inflammatory bowel disease. Gut 1997;40:619-22.

2 Felder JB, Korelitz BI, Rajapakse R, et al. Effects of nonsteroidal antiinflammatory drugs on inflammatory bowel disease: a case-control study. Am J Gastroenterol 2000;95: 1949-54.

3 Newberry RD, Stenson WF, Lorenz RG. Cyclooxygenase-2-dependent arachidonic acid metabolites are essential modulators of the intestinal immune response to dietary antigen. Nat Med 1999:5:900-6.

4 Newberry RD, McDonough JS, Stenson WF, Lorenz RG. Spontaneous and continuous cyclooxygenase-2-dependent prostaglandin e(2) production by stromal cells in the murine small intestine lamina propria: directing the tone of the intestinal immune response. J Immunol $2001 ; 166: 4465-72$

5 Morteau O. COX-2: promoting tolerance. Nat Med 1999;5:867-8.

6 Bertran X, Mane J, Fernandez-Banares F, et al. Intracolonic administration of zileuton, a selective 5-lipoxygenase inhibitor, accelerates healing in a rat model of chronic colitis. Gut 1996:38:899-904

7 Zingarelli B, Squadrito F, Graziani P, et al. Effects of zileuton, a new 5 -lipoxygenase inhibitor, in experimentally induced colitis in rats. Agents Actions 1993;39:150-6.

8 Hawkey CJ, Dube LM, Rountree LV, et al. A trial of zileuton versus mesalazine or placebo in the maintenance of remission of ulcerative colitis. The European Zileuton Study Group for Ulcerative Colitis. Gastroenterology 1997;112:718-24.

9 Hoet B, Arnout J, Deckmyn H, Vermylen J. Synergistic antiplatelet effect of ridogrel, a combined thromboxane receptor antagonist and thromboxane synthase inhibitor, and UDCG-212, a

cAMP-phosphodiesterase inhibitor. Thromb Haemost 1993;70:822-5.

10 Vanden Bossche H, Willemsens G, Bellens D, Janssen PA. Ridogrel: a selective inhibitor of the cytochrome P450-dependent thromboxane synthesis. Biochem Pharmacol 1992;43:739-44.

11 Herzog R, Leuschner J. Experimental studies on the pharmacokinetics and toxicity of 5-aminosalicylic acid-O-sulfate following local and systemic application. Eur J Gastroenterol Hepatol 1995;7:221-6.

12 Carty E, Macey M, McCartney SA, Rampton DS. Ridogrel, a dual thromboxane synthase inhibitor and receptor antagonist: anti-inflammatory profile in inflammatory bowel disease. Aliment Pharmacol Ther 2000;14:807-17.

13 Auwerda JJ, Zijlstra FJ, Tak CJ, et al. Ridogrel enemas in distal ulcerative colitis. Eur J Gastroenterol Hepatol 2001;13:397-400.

14 Kuipers B, Van der Poll T, Levi $M$, et al. Platelet-activating factor antagonist TCV-309 attenuates the induction of the cytokine network in experimental endotoxemia in chimpanzees. J Immuno 1994; 152:2438-46

15 Eliakim R, Karmeli F, Razin E, Rachmilewitz D. Role of platelet-activating factor in ulcerative colitis. Enhanced production during active disease and inhibition by sulfasalazine and prednisolone. Gastroenterology 1988;95: $1167-72$

16 Wallace JL. Release of platelet-activating factor (PAF) and accelerated healing induced by a PAF antagonist in an animal model of chronic colitis. Can J Physiol Pharmacol 1988;66:422-5.

17 Meenan J, Grool TA, Hommes DW, et al. Lexipafant (BB-882), a platelet activating factor receptor antagonist, ameliorates mucosal inflammation in an animal model of colitis. Eur $J$ Gastroenterol Hepato 1996;8:569-73

18 Longo WE, Polities G, Vernava AM III, et al. Platelet-activating factor mediates trinitrobenzene induced colitis. Prostaglandins Leukot Essent Fatty Acids 1994;51:419-24

19 Middleton SJ, Shorthouse M, Hunter JO. Increased nitric oxide synthesis in ulcerative colitis. Lancet 1993;341:465-6.

20 Lundberg JO, Hellstrom PM, Lundberg JM, Alving K. Greatly increased luminal nitric oxide in ulcerative colitis. Lancet 1994;344:1673-4.

21 Rachmilewitz D, Stamler JS, Bachwich D, et al. Enhanced colonic nitric oxide generation and nitric oxide synthase activity in ulcerative colitis and Crohn's disease. Gut 1995;36:718-23.

22 Iwashita E, Miyahara T, Hino K, et al. High nitric oxide synthase activity in endothelial cells in ulcerative colitis. J Gastroenterol 1995;30:551-4.
23 Godkin AJ, De Belder AJ, Villa L, et al. Expression of nitric oxide synthase in ulcerative colitis. Eur J Clin Invest 1996;26:867-72.

24 Ikeda I, Kasajima T, Ishiyama S, et al. Distribution of inducible nitric oxide synthase in ulcerative colitis. Am J Gastroenterol 1997;92:1339-41.

25 Mourelle M, Casellas F, Guarner F, et al. Induction of nitric oxide synthase in colonic smooth muscle from patients with toxic megacolon. Gastroenterology 1995; 109: 1497-502.

26 Leonard N, Bishop AE, Polak JM, Talbot IC. Expression of nitric oxide synthase in inflammatory bowel disease is not affected by corticosteroid treatment. J Clin Pathol 1998;51:750-3.

27 Salzman AL, Eavespyles T, Linn SC, et al. Bacterial induction of inducible nitric oxide synthase in cultured human intestinal epithelial cells. Gastroenterology 1998;114:93-102.

28 Pan MH, Lin-Shiau SY, Lin JK. Comparative studies on the suppression of nitric oxide synthase by curcumin and its hydrogenated metabolites through down-regulation of IkappaB kinase and NFkappaB activation in macrophages. Biochem Pharmacol 2000;60:1665-76.

29 Rachmilewitz D, Stamler JS, Karmeli F, et al. Peroxynitrite-induced rat colitis-a new model of colonic inflammation. Gastroenterology 1993; 105:1681-8.

30 Hogaboam CM, Jacobson K, Collins SM, Blennerhassett MG. The selective beneficial effects of nitric oxide inhibition in experimental colitis. Am J Physiol 1995;268:G673-84.

31 Rachmilewitz D, Karmeli F, Okon E, Bursztyn M. Experimental colitis is ameliorated by inhibition of nitric oxide synthase activity. Gut 1995;37:247-55

32 Kiss J, Lamarque D, Delchier JC, Whittle BJ. Time-dependent actions of nitric oxide synthase inhibition on colonic inflammation induced by trinitrobenzene sulphonic acid in rats. Eur J Pharmacol 1997;336:219-24.

33 Blanchard HS, Dernis-Labous E, Lamarque D, et al. Inducible nitric oxide synthase attenuates chronic colitis in human histocompatibility antigen HLA-B27/human beta2 microglobulin transgenic rats. Eur Cytokine Netw $2001 ; 12: 111-18$

34 Dikopoulos N, Nussler AK, Liptay S, et al. Inhibition of nitric oxide synthesis by aminoguanidine increases intestinal damage in the acute phase of rat TNB-colitis. Eur J Clin Invest 2001;31:234-9.

35 Nakamura $\mathbf{H}$, Tsukada $\mathrm{H}$, Oya $M$, et al. Aminoguanidine has both an anti-inflammatory effect on experimental colitis and a proliferative effect on colonic mucosal cells. Scand J Gastroenterol 1999;34:1117-22.

36 Wallace JL, Vergnolle N, Muscara MN, et al. Enhanced anti-inflammatory effects of a nitric oxide-releasing derivative of mesalamine in rats. Gastroenterology 1999;117:557-66.

37 Ribbons KA, Currie MG, Connor JR, et al. The effect of inhibitors of inducible nitric oxide synthase on chronic colitis in the rhesus monkey. J Pharmacol Exp Ther 1997;280: 1008-15.

38 Roberts PJ, Riley GP, Morgan K, et al. The physiological expression of inducible nitric oxide synthase (iNOS) in the human colon. J Clin Pathol 2001;54:293-7.

39 Auwerx J. PPARgamma, the ultimate thrifty gene. Diabetologia 1999;42:1033-49.

40 Chinetti G, Griglio S, Antonucci M, et al. Activation of proliferator-activated receptors alpha and gamma induces apoptosis of human monocyte-derived macrophages. J Biol Chem 1998;273:25573-80.

41 Chinetti G, Fruchart JC, Staels B. Peroxisome proliferator-activated receptors (PPARs): nuclear receptors at the crossroads between lipid metabolism and inflammation. Inflamm Res 2000;49:497-505.

42 Faveeuw C, Fougeray S, Angeli V, et al. Peroxisome proliferator-activated receptor gamma activators inhibit interleukin-12 production in murine dendritic cells. FEBS Lett 2000;486:261-6.

43 Jain S, Pulikuri S, Zhu Y, et al. Differential expression of the peroxisome proliferator-activated receptor gamma (PPARgamma) and its coactivators steroid receptor coactivator-1 and PPAR-binding protein PBP in the brown fat, urinary bladder, colon, and breast of the mouse. Am J Pathol 1998; 153:349-54

44 DuBois RN, Gupta R, Brockman J, et al. The nuclear eicosanoid receptor, PPARgamma, is aberrantly expressed in colonic cancers. Carcinogenesis 1998; 19:49-53.

45 Desreumaux $\mathbf{P}$, Dubuquoy L, Nutten S, et al. Attenuation of colon inflammation through activators of the retinoid $X$ receptor (RXR)/peroxisome proliferator-activated receptor gamma (PPARgamma) heterodimer. A basis for new therapeutic strategies. J Exp Med 2001; 193:827-38

46 Cha BS, Ciaraldi TP, Carter L, et al. Peroxisome proliferator-activated receptor (PPAR) gamma and retinoid $X$ receptor ( $R X R$ ) agonists have complementary effects on glucose and lipid metabolism in human skeletal muscle. Diabetologia 2001;44:444-52.

47 Lawrence JM, Reckless JP. Pioglitazone. Int J Clin Pract 2000;54:614-18.

48 Wolffenbuttel BH, Sels JP, Huiiberts MS. Rosiglitazone. Expert Opin Pharmacother 2001;2:467-78.

49 Bar-Tana J. Peroxisome proliferator-activated receptor gamma (PPARgamma) activation and its consequences in humans. Toxicol Lett 2001;120:9-19.

50 Fujiwara T, Horikoshi $\mathrm{H}$. Troglitazone and related compounds: therapeutic potential beyond diabetes. Life Sci 2000;67:2405-16.

51 Becker C, Barbulescu K, Wirtz S, et al. Constitutive and inducible in vivo protein-DNA interactions at the tumor necrosis factor-alpha promoter in primary human T lymphocytes. Gene Expr 1999;8:1 15-27.

52 Scheid MP, Foltz IN, Young PR, et al. Ceramide and cyclic adenosine monophosphate (cAMP) induce cAMP response element binding protein phosphorylation via distinct signaling pathways while having opposite effects on myeloid cell survival. Blood 1999;93:217-25. 
53 Neuner P, Klosner G, Schaver E, et al. Pentoxifylline in vivo down-regulates the release of IL-1 beta, IL-6, IL-8 and tumour necrosis factor-alpha by human peripheral blood mononuclear cells. Immunology 1994:83:262-7

54 Levi $M$, Ten Cate $H$, Baver KA, et al. Inhibition of endotoxin-induced activation of coagulation and fibrinolysis by pentoxifylline or by a monoclonal anti-tissue factor antibody in chimpanzees. J Clin Invest 1994;93:114-20.

55 Han J, Thompson P, Beutler B. Dexamethasone and pentoxifylline inhibit endotoxin-induced cachectin/tumor necrosis factor synthesis at separate points in the signaling pathway. J Exp Med 1990;172:391-4.

56 Han J, Huez G, Beutler B. Interactive effects of the tumor necrosis factor promoter and 3'-untranslated regions. J Immunol 1991;146:1843-8.

57 Van Leenen D, Van der Poll T, Levi M, et al. Pentoxifylline attenuates neutrophil activation in experimental endotoxemia in chimpanzees.J Immunol 1993;151:2318-25.

58 Rossignol L, Plantavid M, Chap H, Douste-Blazy L. Effects of two methylxanthines, pentoxifylline and propentofylline, on arachidonic acid metabolism in platelets stimulated by thrombin. Biochem Pharmacol 1988;37:3229-36

59 Hammerschmidt DE, Kotasek D, McCarthy T, et al. Pentoxifylline inhibits granulocyte and platelet function, including granulocyte priming by platelet activating factor. J Lab Clin Med 1988;112:254-63.

60 Krakaver T. Pentoxifylline inhibits ICAM-1 expression and chemokine production induced by proinflammatory cytokines in human pulmonary epithelial cells. Immunopharmacology 2000;46:253-61

61 Hidi R, Timmermans S, Liv E, et al. Phosphodiesterase and cyclic adenosine monophosphate-dependent inhibition of T-lymphocyte chemotaxis. Eur Respir J 2000;15:342-9.

62 Kasyapa CS, Stentz CL, Davey MP, Carr DW. Regulation of IL-15-stimulated TNF-alpha production by rolipram. J Immunol 1999; 163:2836-43

63 Armstrong AM, Foulkes R, Jennings $G$, et al. Tumour necrosis factor inhibitors reduce the acute-phase response in hapten-induced colitis. $\mathrm{Br} J$ Surg 2001;88:235-40.

64 Diaz-Granados N, Howe K, Lu J, McKay DM. Dextran sulfate sodium-induced colonic histopathology, but not altered epithelial ion transport, is reduced by inhibition of phosphodiesterase activity. Am J Pathol 2000;156:2169-77.

65 Peterson TC, Davey K. Effect of acute pentoxifylline treatment in an experimental model of colitis. Aliment Pharmacol Ther 1997;1 1:575-80.

66 Murthy S, Cooper HS, Yoshitake H, et al. Combination therapy of pentoxifylline and TNFalpha monoclonal antibody in dextran sulphate-induced mouse colitis. Aliment Pharmacol Ther 1999; 13:251-60.

67 Reuter BK, Wallace JL. Phosphodiesterase inhibitors prevent NSAID enteropathy independently of effects on TNF-alpha release. Am J Physiol 1999:277:G847-54.

68 Hartmann G, Bidlingmaier C, Siegmund B, et al. Specific type IV phosphodiesterase inhibitor rolipram mitigates experimental colitis in mice. J Pharmacol Exp Ther 2000;292:22-30.

69 Barnette MS, Christensen SB, Essayan DM, et al. SB 207499 (Ariflo), a potent and selective second-generation phosphodiesterase 4 inhibitor: in vitro anti-inflammatory actions. J Pharmacol Exp Ther 1998;284:420-6.

70 Griswold DE, Webb EF, Badger AM, et al. SB 207499 (Ariflo), a second generation phosphodiesterase 4 inhibitor, reduces tumor necrosis factor alpha and interleukin-4 production in vivo. J Pharmacol Exp Ther 1998;287:705-11.

71 Bauditz J, Haemling J, Ortner $M$, et al. Treatment with tumour necrosis factor inhibitor oxpentifylline does not improve corticosteroid dependen chronic active Crohn's disease. Gut 1997:40:470-4.

72 Reimund JM, Dumont S, Muller CD, et al. In vitro effects of oxpentifylline on inflammatory cytokine release in patients with inflammatory bowel disease. Gut 1997;40:475-80.

73 Sheskin J, Convit J. Results of a double blind study of the influence of thalidomide on the lepra reaction. Int J Lepr Other Mycobact Dis 1969;37: 135-46.

74 Sheskin J. Further observation with thalidomide in lepra reactions. Lepr $\operatorname{Rev} 1965 ; 36: 183-7$

75 Sampaio EP, Sarno EN, Galilly R, et al. Thalidomide selectively inhibits tumor necrosis factor alpha production by stimulated human monocytes. J Exp Med 1991;173:699-703.

76 Rowland TL, McHugh SM, Deighton J, et al. Differential effect of thalidomide and dexamethasone on the transcription factor NF-kappa B. Int Immunopharmacol 2001;1:49-61.

77 Moreira AL, Sampaio EP, Zmuidzinas A, et al. Thalidomide exerts its inhibitory action on tumor necrosis factor alpha by enhancing mRNA degradation. J Exp Med 1993;177:1675-80.

78 Rowland TL, McHugh SM, Deighton J, et al. Selective down-regulation of T cell- and non-T cell-derived tumour necrosis factor alpha by thalidomide: comparisons with dexamethasone. Immunol Lett 1999;68:325-32.

79 Muller GW, Shire MG, Wong LM, et al. Thalidomide analogs and PDE4 inhibition. Bioorg Med Chem Lett 1998:8:2669-74.

80 Marriott JB, Westby M, Cookson S, et al. CC-3052: a water-soluble analog of thalidomide and potent inhibitor of activation-induced TNF-alpha production. J Immunol 1998;161:4236-43

81 Corral LG, Haslett PA, Muller GW, et al. Differential cytokine modulation and T cell activation by two distinct classes of thalidomide analogues that are potent inhibitors of TNF-alpha. J Immunol $1999 ; 163: 380-6$.
82 Haslett PA, Corral LG, Albert M, Kaplan G. Thalidomide costimulates primary human $T$ lymphocytes, preferentially inducing proliferation cytokine production, and cytotoxic responses in the CD8+ subset. $J$ Exp Med 1998;187:1885-92.

83 Verbon A, Juffermans NP, Speelman $P$, et al. A single oral dose of thalidomide enhances the capacity of lymphocytes to secrete gamma interferon in healthy humans. Surg Endosc 2000;14:721-5.

84 Gori A, Rossi MC, Trabattoni D, et al. Tumor necrosis factor-alpha increased production during thalidomide treatment in patients with tuberculosis and human immunodeficiency virus coinfection. J Infect Dis 2000; 182:639-40.

85 Bekker LG, Haslett P, Maartens G, et al. Thalidomide-induced antigen-specific immune stimulation in patients with human immunodeficiency virus type 1 and tuberculosis. J Infect Dis 2000;181:954-65

86 Chao NJ, Parker PM, Niland JC, et al. Paradoxical effect of thalidomide prophylaxis on chronic graft-vs.-host disease. Biol Blood Marrow Transplant 1996:2:86-92.

87 Calabrese L, Fleischer AB. Thalidomide: current and potential clinical applications. Am J Med 2000;108:487-95.

88 Hamuryudan V, Mat C, Saip S, et al. Thalidomide in the treatment of the mucocutaneous lesions of the Behcet syndrome. A randomized, double-blind, placebo-controlled trial. Ann Intern Med 1998; 128:443-50

89 Larsson $\mathbf{H}$. Treatment of severe colitis in Behcet's syndrome with thalidomide (CG-2 17). J Intern Med 1990;228:405-7.

90 Postema PT, den Haan P, van Hagen PM, van Blankenstein M Treatment of colitis in Behcet's disease with thalidomide. Eur J Gastroenterol Hepatol 1996:8:929-31.

91 Rustin MH, Gilkes JJ, Robinson TW. Pyoderma gangrenosum associated with Behcet's disease: treatment with thalidomide. J Am Acad Dermatol 1990;23:941-4.

92 Kaplan G, Thomas S, Fierer DS, et al. Thalidomide for the treatment of AIDS-associated wasting. AIDS Res Hum Retroviruses 2000;16:134555.

93 Haslett P, Hempstead M, Seidman C, et al. The metabolic and immunologic effects of short-term thalidomide treatment of patients infected with the human immunodeficiency virus. AIDS Res Hum Retroviruses 1997; 13:1047-54.

94 Jacobson JM, Greenspan JS, Spritzler J, et al. Thalidomide for the treatment of oral aphthous ulcers in patients with human immunodeficiency virus infection. National Institute of Allergy and Infectious Diseases AIDS Clinical Trials Group. J Infect Dis $1999 ; 180: 61-7$

95 Ramirez-Amador VA, Esquivel-Pedraza L, Ponce-de-Leon S, et al. Thalidomide as therapy for human immunodeficiency virus-related oral ulcers: a double-blind placebo-controlled clinical trial. Immunity 1997; 7:837-47.

96 Keesal N, Wasserman M, Bookman A, et al. Thalidomide in the treatment of refractory rheumatoid arthritis. J Rheumatol $1999 ; 26: 2344-7$

97 Huizinga TW, Dijkmans BA, van der Velde EA, et al. An open study of pentoxyfylline and thalidomide as adjuvant therapy in the treatment of rheumatoid arthritis. Ann Rheum Dis 1996;55:833-6.

98 Facchini S, Candusso M, Martelossi S, et al. Efficacy of long-term treatment with thalidomide in children and young adults with Crohn disease: preliminary results. J Pediatr Gastroenterol Nutr 2001;32:178-81.

99 Ehrenpreis ED, Kane SV, Cohen LB, et al. Thalidomide therapy for patients with refractory crohn's disease: an open-label trial. Gastroenterology 1999;117:1271-7.

100 Vasiliauskas EA, Kam LY, Abreu-Martin MT, et al. An open-label pilot study of low-dose thalidomide in chronically active, steroid-dependent Crohn's disease. Gastroenterology 1999;117:1278-87.

101 Vasiliauskas EA, Kam LY, Abreu-Martin MT, et al. An open-label pilot study of low-dose thalidomide in chronically active, steroid-dependent Crohn's disease. Gastroenterology 1999;117:1278-87.

102 Gearing AJ, Beckett $P$, Christodoulou M, et al. Processing of tumour necrosis factor-alpha precursor by metalloproteinases. Nature 1994;370:555-7.

103 McGeehan GM, Becherer JD, Bast RC Jr, et al. Regulation of tumour necrosis factor-alpha processing by a metalloproteinase inhibitor. Nature 1994;370:558-61

104 Gearing AJ, Beckett $P$, Christodoulou M, et al. Matrix metalloproteinases and processing of pro-TNF-alpha. J Leukoc Biol 1995;57:774-7.

105 Dekkers PE, ten Hove T, Lauw FN, et al. The metalloproteinase inhibitor G15402 inhibits endotoxin-induced soluble CD27 and CD16 release in healthy humans. Infect Immun 2000;68:3036-9.

106 Hansen HP, Dietrich S, Kisseleva T, et al. CD30 shedding from Karpas 299 lymphoma cells is mediated by TNF-alpha-converting enzyme. $J$ Immunol 2000; 165:6703-9.

107 Schlondorff J, Becherer JD, Blobel CP. Intracellular maturation and localization of the tumour necrosis factor alpha convertase (TACE). Biochem J 2000;347:131-8

108 Dekkers PE, Lauw FN, ten Hove T, et al. The effect of a metalloproteinase inhibitor (GI5402) on tumor necrosis factor-alpha (TNF-alpha) and TNF-alpha receptors during human endotoxemia. Blood 1999; $94: 2252-8$

109 Heuschkel RB, MacDonald TT, Monteleone G, et al. Imbalance of stromelysin-1 and TIMP-1 in the mucosal lesions of children with inflammatory bowel disease. Gut 2000;47:57-62.

110 Pender SL, Breese EJ, Gunther U, et al. Suppression of T cell-mediated injury in human gut by interleukin 10: role of matrix metalloproteinases. Gastroenterology 1998;115:573-83. 
111 Pender SL, McKenzie C, Shaida A, MacDonald TT. Regulation of matrix metalloproteinases in human intestinal mucosa. Ann N Y Acad Sci 1999;878:581-2.

112 Sykes AP, Bhogal R, Brampton C, et al. The effect of an inhibitor of matrix metalloproteinases on colonic inflammation in a trinitrobenzenesulphonic acid rat model of inflammatory bowel disease. Aliment Pharmacol Ther 1999;13:1535-42.

113 Brown PD. Ongoing trials with matrix metalloproteinase inhibitors. Expert Opinion on Investigational Drugs 2000;9:2167-77.

114 Williams LM, Gibbons DL, Gearing A, et al. Paradoxical effects of a synthetic metalloproteinase inhibitor that blocks both p55 and p75 TNF receptor shedding and TNF alpha processing in RA synovial membrane cell cultures. J Clin Invest 1996;97:2833-41.

115 Lee JC, Laydon JT, McDonnell PC, et al. A protein kinase involved in the regulation of inflammatory cytokine biosynthesis. Nature 1994;372:739-46.

116 Han J, Lee JD, Bibbs L, Ulevitch RJ. A MAP kinase targeted by endotoxin and hyperosmolarity in mammalian cells. Science 1994;265:808-11.

117 Han J, Richter B, Li Z, et al. Molecular cloning of human p38 MAP kinase. Biochim Biophys Acta 1995;1265:224-7.

118 Guha M, Mackman N. LPS induction of gene expression in human monocytes. Cell Signal 2001;13:85-94.

119 Davis RJ. Signal transduction by the JNK group of MAP kinases. Cell 2000;103:239-52.

120 Schulze-Osthoff K, Ferrari D, Riehemann K, Wesselborg S. Regulation of NF-kappa B activation by MAP kinase cascades. Immunobiology 1997; 198:35-49.

121 Rincon M, Flavell RA, Davis RA. The JNK and P38 MAP kinase signaling pathways in T cell-mediated immune responses. Free Radic Biol Med 2000;28:1328-37.

122 Baeuerle PA. IkappaB-NF-kappaB structures: at the interface of inflammation control. Cell 1998;95:729-31.

123 Ghosh S, May M, Kopp EB. NF-kappa B and Rel proteins: evolutionarily conserved mediators of immune responses. Annu Rev Immunol 1998:16:225-60.

124 Schreiber S, Nikolaus S, Hampe J. Activation of nuclear factor kappa B inflammatory bowel disease. Gut 1998;42:477-84.

125 Rogler G, Brand K, Vogl D, et al. Nuclear factor kappaB is activated in macrophages and epithelial cells of inflamed intestinal mucosa. Gastroenterology 1998;115:357-69.

126 Elewaut D, DiDonato JA, Kim JM, et al. NF-kappa B is a central regulator of the intestinal epithelial cell innate immune response induced by infection with enteroinvasive bacteria. J Immunol 1999;163:145766.

127 Jobin C, Hellerbrand C, Licato LL, et al. Mediation by Nf-kappa-B of cytokine induced expression of intercellular adhesion molecule 1 (lcam-1) in an intestinal epithelial cell line, a process blocked by proteasome inhibitors. Gut 1998;42:779-87.
128 Neish AS, Gewirtz AT, Zeng H, et al. Prokaryotic regulation of epithelial responses by inhibition of IkappaB-alpha ubiquitination. Science 2000;289:1560-3.

129 Neurath MF, Pettersson S, Meyer zum Buschenfelde KH, Strober W. Local administration of antisense phosphorothioate oligonucleotides to the p65 subunit of NF-kappa B abrogates established experimental colitis in mice. Nat Med 1996;2:998-1004.

130 Murano M, Maemura K, Hirata I, et al. Therapeutic effect of intracolonically administered nuclear factor kappa B (p65) antisense oligonucleotide on mouse dextran sulphate sodium (DSS)-induced colitis. Clin Exp Immunol 2000;1 20:51-8.

131 Janssen-Heininger YM, Poynter ME, Baeuerle PA. Recent advances towards understanding redox mechanisms in the activation of nuclear factor kappaB. Free Radic Biol Med 2000;28:1317-27.

132 Jobin C, Bradham CA, Russo MP, et al. Curcumin blocks cytokine-mediated NF-kappa B activation and proinflammatory gene expression by inhibiting inhibitory factor l-kappa B kinase activity. $J$ Immunol 1999:163:3474-83.

133 Kanauchi O, Andoh A, Iwanaga T, et al. Germinated barley foodstuffs attenuate colonic mucosal damage and mucosal nuclear factor kappa B activity in a spontaneous colitis model. J Gastroenterol Hepatol 1999:14:1173-9.

134 Segain JP, Raingeard de la Bletiere D, Bourreille A, et al. Butyrate inhibits inflammatory responses through NFkappaB inhibition: implications for Crohn's disease. Gut 2000;47:397-403

135 Waetzig GH, Seegert D, Nikolaus S, et al. Differential activity and expression of mitogen-activated protein kinases in inflammatory bowel disease. Gastroenterology 2001;120:A-522.

136 Badger AM, Griswold DE, Kapadia R, et al. Disease-modifying activity of SB 242235, a selective inhibitor of p38 mitogen-activated protein kinase, in rat adjuvant-induced arthritis. Arthritis Rheum 2000;43:175-83

137 Badger AM, Bradbeer JN, Votta B, et al. Pharmacological profile of SB 203580, a selective inhibitor of cytokine suppressive binding protein/p38 kinase, in animal models of arthritis, bone resorption, endotoxin shock and immune function. J Pharmacol Exp Ther 1996;279: 1453-61.

138 Wang X, Rao J, Studzinski GP. Inhibition of p38 MAP kinase activity up-regulates multiple MAP kinase pathways and potentiates 1,25-dihydroxyvitamin D(3)-induced differentiation of human leukemia HL60 cells. Exp Cell Res 2000;258:425-37.

139 Murakami-Mori K, Mori S, Nakamura S. p38MAP kinase is a negative regulator for ERK 1/2-mediated growth of AIDS-associated Kaposi's sarcoma cells. Biochem Biophys Res Commun 1999;264:676-82.

140 Hommes DW, Van den Blink B, Van de Heisteeg B, et al. A new MAP kinase inhibitor, $C N I 1493$, is safe and effective in the treatment of moderate to severe Crohn's disease. Gastroenterology 2001;120:A-452. 